\title{
Measurements on Active Cold Loads for Radiometer Calibration
}

\section{Skou, Niels; Søbjærg, Sten Schmidl; Balling, Jan E.}

Published in:

Microwave Radiometry and Remote Sensing of the Environment

Link to article, DOI:

10.1109/MICRAD.2008.4579465

Publication date:

2008

Document Version

Publisher's PDF, also known as Version of record

Link back to DTU Orbit

Citation (APA):

Skou, N., Søbjærg, S. S., \& Balling, J. E. (2008). Measurements on Active Cold Loads for Radiometer Calibration. In Microwave Radiometry and Remote Sensing of the Environment: MICRORAD 2008 [4579465] IEEE Press. https://doi.org/10.1109/MICRAD.2008.4579465

\section{General rights}

Copyright and moral rights for the publications made accessible in the public portal are retained by the authors and/or other copyright owners and it is a condition of accessing publications that users recognise and abide by the legal requirements associated with these rights.

- Users may download and print one copy of any publication from the public portal for the purpose of private study or research.

- You may not further distribute the material or use it for any profit-making activity or commercial gain

- You may freely distribute the URL identifying the publication in the public portal 


\title{
Measurements on Active Cold Loads for Radiometer Calibration
}

\author{
Niels Skou, Fellow, IEEE, Sten S. Søbjærg, Member, IEEE, and Jan Balling
}

\begin{abstract}
Two semi-conductor Active Cold Loads (ACLs) to be used as cold references in spaceborne microwave radiometers have been developed. An X-band frequency was chosen, and the target noise temperature value was in the 50 to $100 \mathrm{~K}$ range. The ACLs are characterized in the operating temperature range 0 $50{ }^{\circ} \mathrm{C}$, and long term stability is assessed. To this end a Test Bed has been developed. This Test Bed is actually a stable radiometer, and its design is briefly reviewed. The test setup is described, and preliminary test campaign results indicate output temperatures of $77 \mathrm{~K}$ and $55 \mathrm{~K}$ for the two ACLs. The temperature sensitivity is slightly below $0.4 \mathrm{~K} /{ }^{\circ} \mathrm{C}$ for the units, and excellent long term stability prevails.
\end{abstract} load.

Index Terms-Microwave, radiometer, calibration, active cold

\section{INTRODUCTION}

A transistor based cold load for radiometer calibration, a socalled active cold load (ACL), has been developed for future space programs.

Typically, a radiometer needs frequent calibration using a hot and a cold reference point. Ideally, these references should encompass the radiometer's expected range of input brightness temperatures - typically some 100 to $300 \mathrm{~K}$ for an Earth sensing system. The hot reference presents little problem and can just be a microwave load at the internal instrument temperature. Cooling a load to below $100 \mathrm{~K}$ in space is not easy, and therefore a view to free space (around $3 \mathrm{~K}$ ), either via a special sky viewing antenna or via a reflector in front of the main feed horn, has typically been applied [1]. But this is not always practical, hence the desire for a small, low power, low weight, stable cold reference.

Two such ACLs - based on transistors connected backwards, i.e. the gate is connected to the output connector have been designed and built by Ylinen Electronics, and their performance is being assessed at the Technical University of Denmark. For this first test development a frequency in the $\mathrm{X}$ band was chosen.

A proper Test Bed for monitoring the ACLs, and for carrying out tests of their performance, has been designed and manufactured [2]. A test campaign, featuring both short term

Manuscript received April 18, 2008. The described work was supported by the European Space Agency.

The authors are with the National Space Institute, B 348, Technical University of Denmark, DK2800 Lyngby, Denmark. Phone: +45 452537 68, e-mail: ns@space.dtu.dk temperature sensitivity tests as well as long term stability tests, has been designed and carried out. The specific objective of this paper is to outline the design of the Test Bed, describe the test set-up and campaign, and report on test results.

\section{SPECIFICATIONS AND REQUIREMENTS}

Based on preliminary considerations, the following set of specifications was worked out as a starting point for the development.

ACL:

- frequency: $10.69 \mathrm{GHz} \pm$ at least $50 \mathrm{MHz}$

- noise temperature below $150 \mathrm{~K}$ - possibly down to $50 \mathrm{~K}$

- nominal operating temperature is $25^{\circ} \mathrm{C}$

- RF interface: coaxial - SMA

- the ACL shall be characterized in the temperature range $0-50{ }^{\circ} \mathrm{C}$

- $\quad$ stability: better than $\pm 1 \mathrm{~K}$ per year

Test Bed:

- frequency: $10.69 \mathrm{GHz} \pm 50 \mathrm{MHz}$

- absolute accuracy: $\pm 1 \mathrm{~K}$ (goal: $\pm 0.6 \mathrm{~K}$ )

- $\quad$ stability better than $\pm 0.1 \mathrm{~K}$ over $5 \mathrm{~min}$

- $\quad$ sensitivity better than $0.1 \mathrm{~K} @ 5 \mathrm{sec}$ integration

- integration time: $0.1-10 \mathrm{sec}$

- 2 ACL inputs

- input reflection coefficient $-30 \mathrm{~dB}$ (target)

- the Test Bed system must record the ACL temperature to better than $0.5^{\circ} \mathrm{C}$ with $0.05^{\circ} \mathrm{C}$ resolution

- the Test Bed system must record ACL bias voltages and currents

- all ACL parameters recorded each sec.

Concerning the test campaign, a characterization of the ACLs in the temperature range of 0 to $50{ }^{\circ} \mathrm{C}$ is to be followed by a long-term (around one year) stability test.

\section{TEST BED}

The output of the ACLs is expected to be in the 50 - $100 \mathrm{~K}$ range, and it has to be measured to within $1 \mathrm{~K}$. It is hoped that the drift of the ACL is below $1 \mathrm{~K}$ per year. The Test Bed is thus in fact a radiometer having an absolute accuracy of better than $1 \mathrm{~K}$. The best radiometer stability and accuracy arises if the noise temperature to be measured, here an ACL around 50 $100 \mathrm{~K}$, is close to the radiometers internal reference - or if the radiometer is often calibrated using a standard close to it. A 
liquid nitrogen target (LN2) around $77 \mathrm{~K}$ would serve well for such a reference or calibration standard.

The long-term tests to be carried out using the Test Bed require continuous measurements of the ACL, and the Test Bed will be operated continuously. Thus a LN2 reference, which has to be attended to by personnel, is not practical - but absolutely viable as an external calibration standard. Measurement fidelity will thus be assured by stability of the Test Bed (including its internal references) in conjunction with this LN2 calibration to be carried out at certain intervals.

\section{A. Microwave Front End}

Two internal references are used: one termination at the temperature of the microwave front end, and one cooled by a Peltier element. Also, an internal noise diode that may be switched on and off is employed. The output of the noise diode - properly attenuated to somewhat below $100 \mathrm{~K}$ - is injected after the input switch and thus added to the signal from any source. This will enhance calibration fidelity, and make linearity check simple.

Following these considerations, the Test Bed block diagram looks like shown in Figure 1.

The Test Bed is a direct detect, total power radiometer with frequent calibration and $1 \mathrm{sec}$ integration time (the integration is in fact carried out in a computer and can be varied). The radiometer has a low loss, coax switch at the input. This switch selects one of 3 external signals (ACLs or LN2 reference) or one of the two internal loads.

The external inputs are supplied with hi-quality isolators ensuring very low input reflection coefficients, and hence well defined working conditions for the ACLs. At the same time the noise temperature being emitted from the Test Bed towards the ACLs and the LN2 target is well defined and equal to the internal front-end physical temperature. The 3 input signal paths are made as equal as possible in order to give good balance between the ACL signals and the primary calibration signal from the LN2 target.
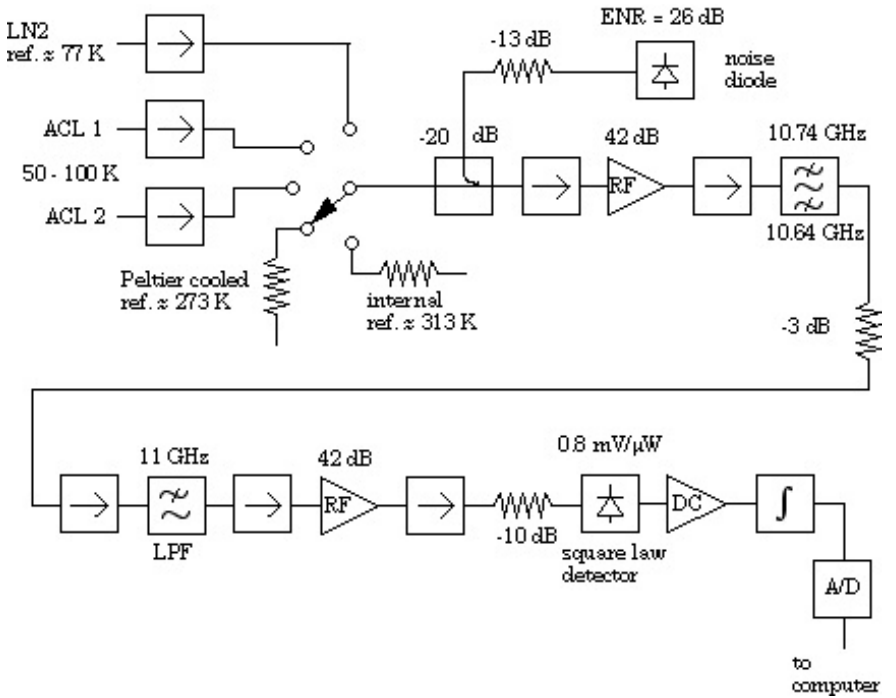

Figure 1. Block diagram
The noise figure of the radiometer is calculated to be 4.6 $\mathrm{dB}$, and the receiver noise is $\mathrm{T}_{\mathrm{N}}=546 \mathrm{~K}$. This corresponds to a sensitivity of $0.086 \mathrm{~K}$ for a $318 \mathrm{~K}$ input signal (hot load) and 1 sec integration time.

\section{B. Control System and Data Recording}

The interface to the outside world is based on a so-called LIAB (Linux-In-A-Box) single board PC. The single-board PC is equipped with industry-standard interfaces such as Ethernet and RS232. The only external connection from the Test Bed system, is thus an RJ45 connector for the Ethernet.

Control and monitoring software which can run on any standard PC with an Ethernet connection has been developed. The software receives input from the user in the form of setup files (e.g. switch control schemes for the calibration schedule) and real-time commands, and it is also capable of displaying system status and output data in real time.

Data can be stored on the same or on any other computer connected to the network, and the transfer is carried out automatically by the Linux single board computer, using standard FTP.

\section{Temperature Stabilized Enclosure}

The microwave - and thus temperature sensitive components are mounted in a carefully temperature regulated inner box. The inner box is placed inside the 19" outer box, holding the remaining components. The only heat flow from the inner box to the outside world is through the air, circulating in the outer box, driven by an internal fan. The circulating air is also temperature stabilized, and this is ensured by variable air exchange to/from the outside world, regulated by a variable speed fan.

The design of the thermal control is based on two independent, digital PI-regulators. One takes care of the heating of the microwave section, and the other controls the variable speed fan. The described system has proven a thermal stability of the front end to better than $0.02{ }^{\circ} \mathrm{C}$ for a $15{ }^{\circ} \mathrm{C}$ change in ambient temperature.

\section{Liquid Nitrogen Target}

The target used for absolute calibration is a microwave absorber in a stainless steel bucket insolated by styrofoam. A standard antenna horn views this target. For calibration, liquid nitrogen is poured into the bucket, it is ensured that the absorber tips are covered, and a metal lid covering the opening around the antenna horn is put in place.

The loss in the system is of paramount importance for the absolute calibration. The antenna horn is practically lossless but the coax-to-waveguide adapter (including a small section of antenna waveguide) is lossy. This loss is very difficult to measure accurately due to the mix of coax and waveguide.

The loss has been assessed in 2 different ways using a network analyzer: (1) measuring the return loss on the short circuited adapter and divide by 2 results in $0.14 \mathrm{~dB}$ loss; (2) measuring the transmission loss on 2 identical adapters mounted back-to-back and divide by 2 results in $0.20 \mathrm{~dB}$ loss. 
These losses results in an increased brightness temperature of $6.3 \mathrm{~K}$ and $9.7 \mathrm{~K}$ respectively. This corresponds to a $\pm 1.7 \mathrm{~K}$ uncertainty, and the required $\pm 1 \mathrm{~K}$ absolute accuracy cannot be assured presently. This awaits more delicate loss measurements. Note that concerning stability this is not a problem as the adapter temperature is quite constant and monitored by the Test Bed.

\section{E. Test Bed Performance}

The measured sensitivity of the Test Bed (hot load at 318 $\mathrm{K})$ is: $0.092 \mathrm{~K}$ for $1 \mathrm{sec}$. integration time.

The Test Bed stability has been assessed, see Figure 2. The standard deviation of the output is calculated for increasing integration when measuring the internal load, and it is seen to be well below $0.1 \mathrm{~K}$ up to more than 6 mins, which is the time between calibrations during the long term stability test (see later).

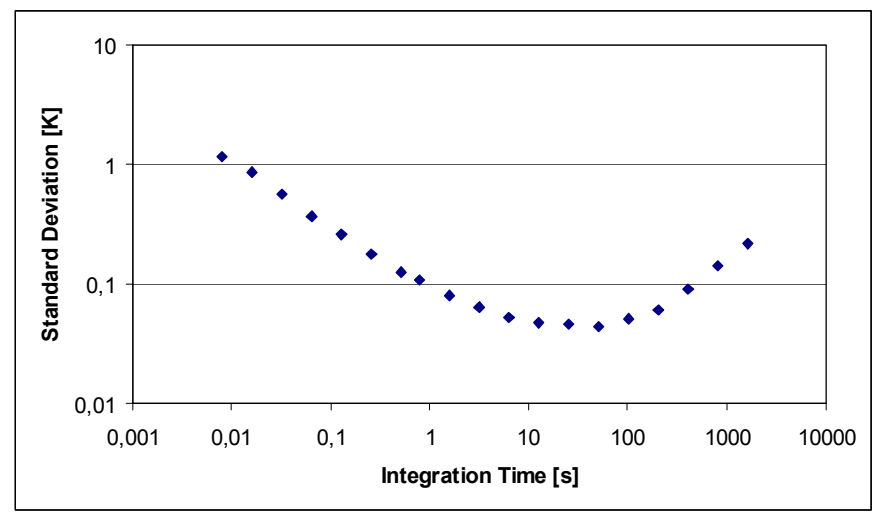

Figure 2. Test Bed Std. Dev. vs. integration time

\section{THE TEST CAMPAigN}

Two major stages are foreseen in the test activities: a relative short campaign in which the Test Bed measures the output of the ACLs under varying physical temperature conditions, and a long term (around 1 year) stability test in which the output of the ACLs are monitored continuously by the Test Bed under ambient temperature conditions.

\section{A. Varying Temperature Test}

The varying temperature campaign can be described a bit further as providing a staircase scheme in which the temperature of the ACLs is increased from $0{ }^{\circ} \mathrm{C}$ to $50{ }^{\circ} \mathrm{C}$ in $10^{\circ} \mathrm{C}$ steps. During this test the ACLs are separated from the Test Bed by $80 \mathrm{~mm}$ long stainless steel, semi rigid (0.087") coax cables in order to have the ACLs inside a climate test chamber and the Test Bed outside, see Figure 3. The loss in these coax lines are corrected for.

Figure 4 shows the ACL1 output. The temperature curve is not shown, but it looks just like a cleaned version of the output curve. For practical reasons the temperature was first increased from ambient up to beyond $50{ }^{\circ} \mathrm{C}$, and then cooling was applied to obtain the lower temperatures.

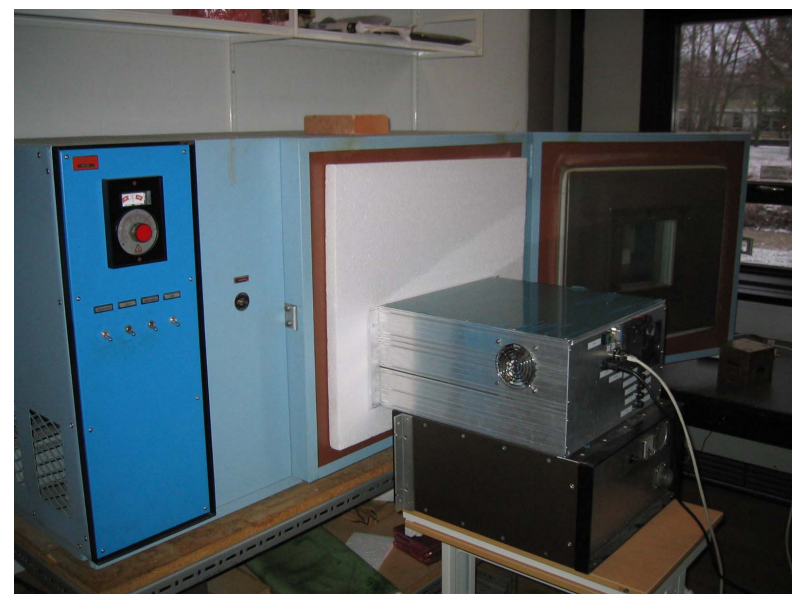

Figure 3. ACLs in test chamber for temperature characterization

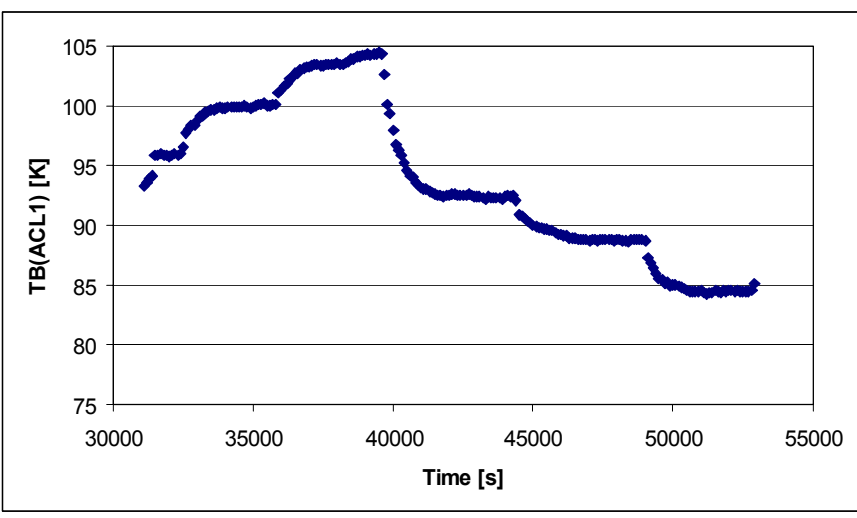

Figure 4. ACL1 output vs. time

In Figure 5 the ACL1 output is plotted against physical temperature. A completely straight line is not found as the data contains all the transits where equilibrium between temperature sensors and internal ACL temperature is not ensured.

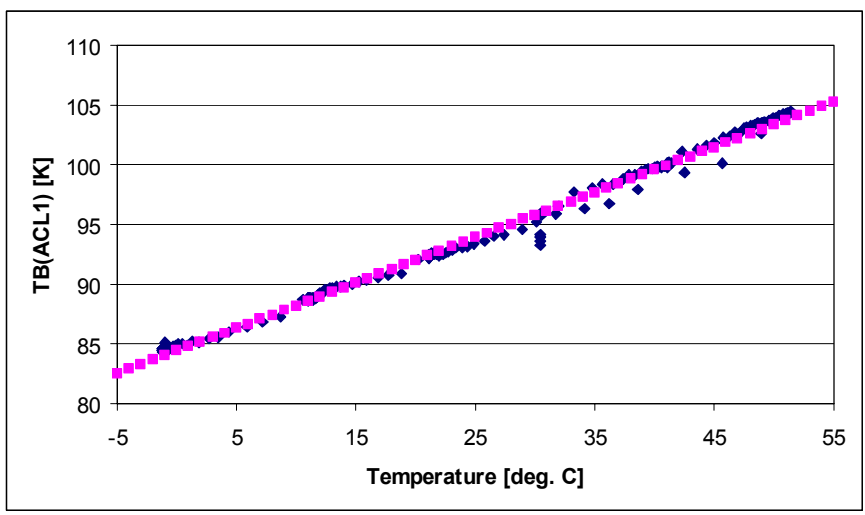

Figure 5. ACL1 output vs. temperature

The measurements show that the output of ACL1 increase linearly with physical temperature, with a sensitivity of $0.38 \mathrm{~K}$ $/{ }^{\circ} \mathrm{C}$. In a similar fashion is found $0.35 \mathrm{~K} /{ }^{\circ} \mathrm{C}$ for ACL2. 


\section{B. Long Term Stability Test}

During the long term stability test the Test Bed and the ACLs are left undisturbed in a quiet basement room. The ACLs are not temperature regulated, but will just be at ambient (typically $21^{\circ} \mathrm{C}$ ). The ACLs are connected directly to the Test Bed (no extra transmission lines), see Figure 6.

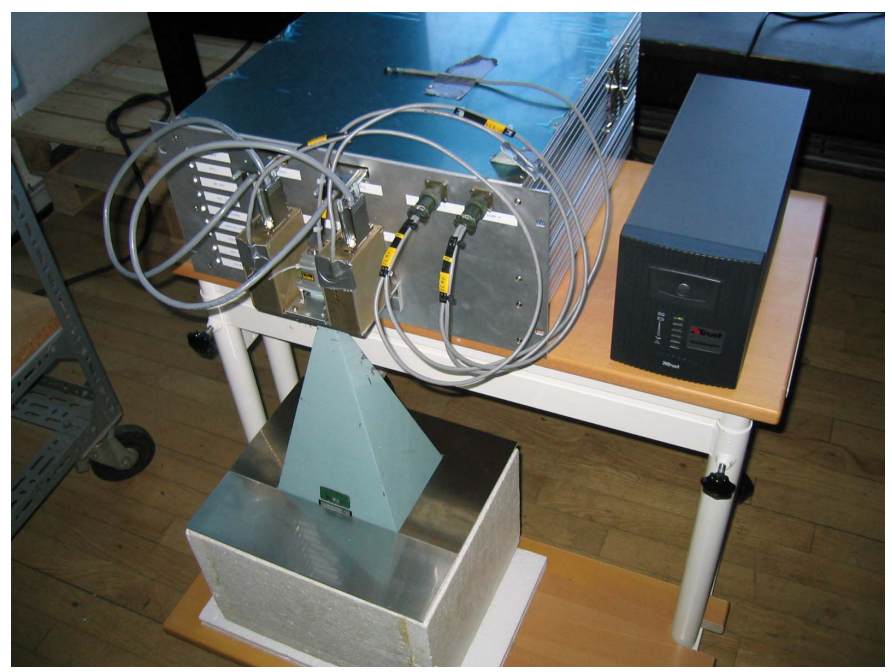

Figure 6. Long term stability set-up

The 3 input connectors of the Test Bed are side by side on the front plate. The ACLs are the two boxes seen on either side of the calibration horn. The calibration target is covered by its metal lid, easily removable for LN2 filling of the bucket. The measurements rely on stability and internal calibration of the Test Bed, augmented by LN2 calibrations at suitable intervals (roughly monthly). During the stability tests a 12 minutes cycle, in which the ACLs are measured alternatively for $5 \mathrm{~min}$. interrupted by $1 \mathrm{~min}$. internal calibration, is used. The validity of this scheme is supported by the Test Bed performance measurements as reported in Section III $E$.

Figure 7 shows the output of ACL1 as a function of time, based on the external LN2 calibration. Dots on the curve indicate the calibrations. The drift over almost one year is less that $1 \mathrm{~K}$. A very similar result is obtained for ACL2.

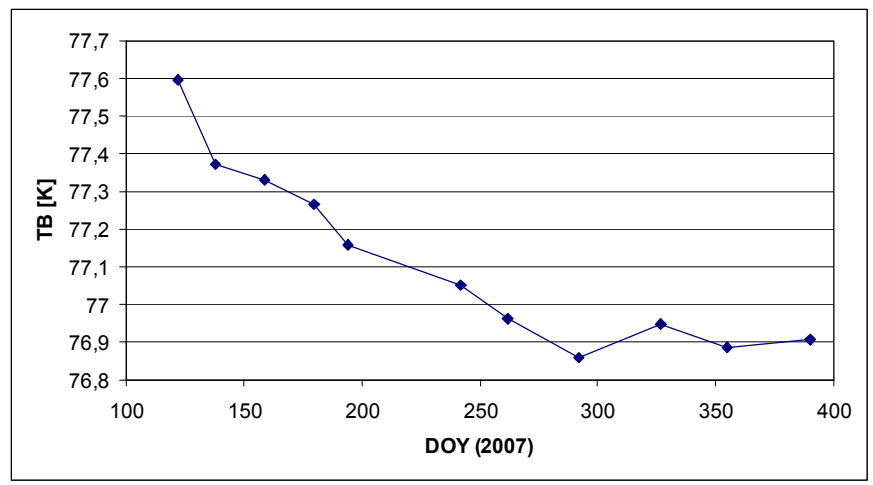

Figure 7. ACL1 output based on LN2 calibration
The output of ACL1 can also be calculated based entirely on the internal calibration (with one LN2 calibration to set the absolute level), see Figure 8.

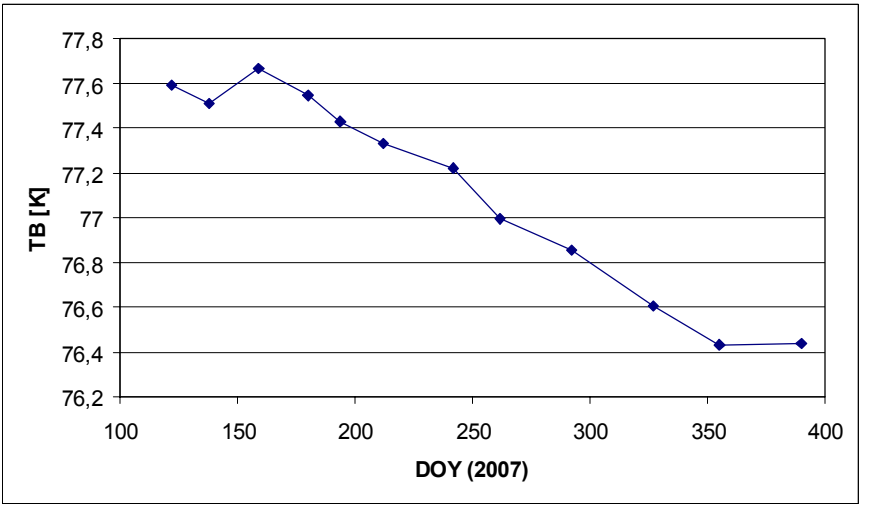

Figure 8. ACL1 output based on internal calibration

A very similar result is obtained: a drop of about $1 \mathrm{~K}$ is experienced over almost one year. This means two things: the Test Bed is in itself very, very stable making regular LN2 calibration almost superfluous, and the drift must be ascribed to the ACL output and not errors in the Test Bed (such as changing loss or reflection coefficient in the calibration horn).

It is found that the output of ACL1 is around $77 \mathrm{~K}$ and of ACL2 around $55 \mathrm{~K}$.

\section{CONCLUSIONS}

Transistor based active cold loads for calibration seems to be a viable option for future radiometer systems - even in space. Two X-band experimental ACLs have been designed and manufactured. Likewise a Test Bed has been developed with the aim of characterizing the ACLs, both concerning thermal behavior and long-term stability. Measurements indicate that the ACLs provide a stable, cold noise temperature of $77 \mathrm{~K}$ and $55 \mathrm{~K}$ respectively, and that the dependence on physical temperature is around $0.4 \mathrm{~K} /{ }^{\circ} \mathrm{C}$. The measurement campaign is ongoing at the time of writing, but excellent stability over time seems to prevail.

\section{ACKNOWLEDGMENT}

The development of the Test Bed was supported through fruitful discussions with Mr. Janne Lahtinen and Mr. Petri Piironen. These gentlemen are herewith acknowledged.

\section{REFERENCES}

[1] N. Skou and D. LeVine, "Microwave Radiometer Systems: Design and Analysis", Artech House, 2006.

[2] N.Skou, S. S. Søbjærg, J. Balling, "Performance Measurements on Active Cold Loads for Radiometer Calibration", Proceedings of IGARSS'07, July 2007, 4p. 